\title{
ESTRUCTURA TERRITORIAL DEL TURISMO EN LA REGIÓN Palenque-Cascadas de Agua Azul, Chiapas, México
}

\author{
Josué Roberto Garza Tovar \\ jossgarzz@yahoo.com.mx \\ Álvaro Sánchez Crispín \\ ascrispin@yahoo.com \\ Alicia Figueroa Encino \\ alice_figueroa369@yahoo.com.mx \\ Universidad Nacional Autónoma de México
}

Este artículo examina la estructura territorial del turismo en la región Palenque-Cascadas de Agua Azul, Chiapas, con uno de los sitios arqueológicos más visitados en México, Patrimonio de la Humanidad por la Unesco y dos áreas naturales protegidas. Los hallazgos de la investigación documental y de campo muestran un hecho paradójico: la fuerte conexión terrestre del área de estudio con otros circuitos turísticos en la Ruta Maya y en Chiapas, frente a la desarticulación espacial de su oferta turística, lo que restringe los eslabonamientos productivos del turismo con la economía local.

Palabras clave: estructura territorial, turismo, Palenque-Cascadas de Agua Azul, Chiapas, México

\section{TERRITORIAL STRUCTURE OF TOURISM IN THE REGION Palenque-Cascadas de Agua Azul, Chiapas, Mexico}

This article examines the territorial structure of tourism in the Palenque-Cascadas de Agua Azul of Chiapas, a region with one of the most visited Mayan cities in Mexico, Unesco World Heritage Site, and two natural protected areas. Based on documentary research and field work, carried out between 2017 and 2019, the main findings show a contradictory fact: while the study area has strong land-connections with other tourist destinations in the Mayan Route, at the same time, it shows weak spatial links among its own tourist resources, which constrains the productive relevance of tourism in the local economy.

Key words: territorial structure, tourism, Palenque-Cascadas de Agua Azul, Chiapas, Mexico 


\section{Introducción}

$\mathrm{M}$ éxico compite en el mercado turístico internacional con un número creciente de países que anualmente incorporan productos similares o novedosos y que, en varios casos, gozan de una mejor imagen para el turista internacional. Por tanto, el gobierno mexicano ha diversificado la oferta nacional de recursos para el turismo a fin de mantener la competitividad de este sector económico, tercera fuente de divisas extranjeras (Coll-Hurtado, 2016; Velázquez y Cardona, 2017).

En este tenor, entidades federativas que antes poco figuraban en el escenario turístico nacional hoy acogen grandes inversiones públicas y privadas, entre ellas, Chiapas que, pese a ser una de las más pobres y tener una historia reciente de conflictos políticos y sociales, registra un flujo sostenido de turistas (Sectur, 2018). En tal entidad se localiza la región Palenque-Cascadas de Agua Azul (RPA) que contiene la cuarta zona arqueológica más visitada en el país y única en Chiapas decretada por la Unesco como Patrimonio de la Humanidad, a la que se asocian dos áreas naturales protegidas federales. Estos escenarios fueron considerados por el Fondo Nacional de Fomento al Turismo (Fonatur), a principios de siglo, para construir un Centro Integralmente Planeado para el turismo, similar a Cancún y Los Cabos, pero bajo el binomio de arqueología y selva que, aunque inconcluso, estimuló la construcción de un aeropuerto internacional, en 2014 , el proyecto de una autopista a San Cristóbal de Las Casas y remodelaciones del equipamiento urbano y turístico. A esto se suma la incorporación, en 2015, de la cabecera municipal de Palenque al programa Pueblos Mágicos de México de la Secretaría de Turismo federal, así como el anuncio del Tren Maya, uno de los megaproyectos turísticos más ambiciosos del nuevo sexenio presidencial (2018-2024).

Tal escenario proyecta a la RPA como uno de los espacios turísticos más dinámicos en Chiapas en función de sus flujos de capitales y turistas. Empero, carece de un interés en el ámbito científico social, en general, y en la geografía mexicana, en particular. En consideración de lo anterior, el propósito de la investigación consiste en identificar, por un lado, los elementos físico-culturales que hacen de este lugar un sitio preferencial para el turismo en México y, por otro, los patrones territoriales generados por este.

El artículo contiene las siguientes secciones: el soporte teórico-metodológico de la investigación; el contexto geográfico regional ligado con el turismo; el nodo turístico con su oferta de recursos, servicios y vías de comunicación; su arreglo espacial en el ámbito urbano y rural; el patrón geográfico de movilidad de los turistas y, al final, 
con base en cada uno de estos componentes, se revela la estructura territorial de tal sector económico, junto con el mapa que los sintetiza. Los hallazgos señalan, por un lado, la posición estratégica y fuerte conexión terrestre del área de estudio con respecto a la Selva Lacandona y la Ruta Maya, que brindan un contexto favorable para el crecimiento del turismo. Por otro lado, se exhibe la desarticulación espacial interna de esta actividad, debido a la implantación de un esquema masivo y selectivo, donde tres perímetros bien acotados en la ciudad de Palenque y dos de 14 centros ecoturísticos identificados en campo monopolizan la promoción, el equipamiento y los flujos de turistas, incluidos en casi el único tour para visitar la RPA y a los que el $80 \%$ de los viajeros encuestados restringió su visita. El panorama anterior, se concluye, entorpece los eslabonamientos productivos del turismo con la economía local y conduce a la saturación de visitantes en unos pocos lugares, mientras que excluye a la mayoría de estos de la dinámica turística regional.

\section{Marco teórico-metodológico}

En geografía, el concepto de organización territorial se desarrolla en la Unión Soviética, desde la primera mitad del siglo XX, con fines de planeación espacial, regionalización económica y aprovechamiento del medio físico (Buch-Hanson y Nelson, 1985). Más tarde, en los años 80 , se emplea para examinar la industria y la agricultura, dentro del marco de la geografía regional (Privalovskaya, 1983; Kostrowicki, 1986). En términos generales, esta herramienta teórica permite estudiar la realidad a partir de dos dimensiones (Kostrowicki, 1986): una abstracta, compuesta por los procesos territoriales que se refieren a la conformación histórica del espacio geográfico. La otra es la parte concreta representada por las estructuras territoriales que materializan los objetivos, intereses y expectativas de la sociedad, en términos políticos, sociales y económicos (Kostrowicki, 1986).

Este trabajo emplea este último concepto para estudiar el turismo, por lo que vale la pena agregar que, en geografía económica, la estructura territorial identifica el carácter espacial de un sector económico en las etapas de producción, consumo y distribución, junto con sus inherentes ventajas e inconvenientes (Sánchez, Mollinedo y Propin, 2012; Mollinedo, 2014; Garza y Sánchez, 2015; Yurkievich y Sánchez, 2016). En específico, Propin y Sánchez (2001, p. 149), aluden que tal concepto sintetiza los "rasgos distintivos del espacio geográfico", por lo que puede expresarse en lenguaje cartográfico y evidenciar las contradicciones sociales de un lugar y sus interacciones en escalas diversas. 
Con relación al turismo, la estructura territorial examina los elementos físicos, técnicos y humanos necesarios para su implantación y expansión en un sitio o región específica (Gallegos y López, 2004). Esto tiene que ver con tres situaciones: una, el acomodo espacial de la oferta de recursos y servicios turísticos; dos, la eficiencia de las vías de comunicaciones y transportes que permiten el arribo, desplazamiento y salida de los turistas y, tres, la intensidad de los flujos de bienes y visitantes en el ámbito nacional e internacional (Sánchez, Mollinedo y Propin, 2012).

Para examinar los elementos anteriores se siguió una metodología que constó de una parte documental y otra de campo. La primera se basó en la consulta de bibliografía, estadísticas y cartografía del medio natural, socioeconómico y turístico del área de estudio. Esto se completó con programas de tipo ambiental y urbano de seis organismos oficiales: Comisión Nacional de Áreas Naturales Protegidas (Conanp), Fondo Nacional de Fomento al Turismo (Fonatur), Instituto Nacional de Estadística y Geografía (INEGI), Secretaría de Medio Ambiente y Recursos Naturales (Semarnat), Secretaría de Turismo (Sectur) y Secretaría de Comunicaciones y Transportes (SCT) para detectar los aspectos técnicos y socioeconómicos de los proyectos de infraestructura y turismo.

En forma paralela, se revisaron guías, revistas y mapas turísticos de la RPA, así como las páginas web de los gobiernos estatal y municipal, empresas privadas (hoteles, restaurantes, agencias de viaje y empresas comunitarias de ecoturismo) y de TripAdvisor. La finalidad fue identificar la oferta turística en el área de estudio, las imágenes y discursos con que se venden al viajero y las experiencias y opiniones de los turistas acerca de los lugares que visitaron y los servicios que contrataron en el área de estudio.

El trabajo de campo incluyó cinco visitas a la RPA, entre 2017 y 2019, para corroborar y ampliar la información de gabinete. Se efectuaron tres en temporada alta (vacaciones de verano, Semana Santa y fin de año) y dos en baja (mayo-junio y noviembre) con el propósito de apreciar los contrastes en la dinámica turística entre ambos períodos. En las salidas se visitaron, en tours y por cuenta propia, los recintos naturales y culturales de interés para el turismo y se llevaron a cabo las actividades de investigación siguientes: una, recopilación y análisis de hemerografía local y publicidad turística; dos, identificación de los centros ecoturísticos y registro de los tiempos, costos y formas de traslado a cada uno; tres, observación participante sobre las conductas de los viajeros en cuanto a su estancia, medio de transporte y consumo; cuatro, aplicación de 20 entrevistas semi-estructuradas a personajes clave del sector para conocer los retos, problemas y proyectos actuales de éste en la escala muni- 
cipal y regional. El universo de las entrevistas englobó dos delegados de turismo de la Región Selva, dos secretarios de la Oficina de Turismo Municipal en Palenque, 13 propietarios y empleados de hoteles, restaurantes y transportadoras turísticas, y tres comisariados ejidales en Cascadas de Agua Azul, Misol-Há y Welib-Há.

En forma complementaria, se aplicaron 102 encuestas a turistas nacionales (58) y extranjeros (44), seleccionados de manera aleatoria, a lo largo de los sitios representativos del turismo en la RPA, como en los aún no masificados por dicha actividad. La encuesta se centró en distinguir el tipo de turista que los visita y los elementos significativos de su viaje desde una óptica espacial. Paralelamente, se examinaron 25 tours y paquetes de viaje hacia el área de estudio, compilados de internet e in situ, para obtener un panorama más amplio sobre los itinerarios, costos y el patrón desplazamiento de los viajeros.

\section{Rasgos físico-geográficos}

La RPA se ciñe a los municipios de Palenque y Salto de Agua (figura 1) y, en términos geomorfológicos, se localiza en la unión de dos grandes provincias fisiográficas: Llanura Costera del Golfo y Sierras del Norte de Chiapas. Esto crea un paisaje de planicies, mesetas y montañas, favorable para el turismo por los contrastes que posee el relieve, cuya altitud asciende hacia el sur, desde el nivel del mar hasta $1500 \mathrm{msnm}$. La morfología es de composición caliza y está sometida a un intenso plegamiento con sinclinales y anticlinales en dirección noroeste-sureste (Morales, Priego y Bollo, 2017). El relieve resultante se distingue por barrancos y valles paralelos, dispuestos en bloques fracturados y escalonados con pendientes pronunciadas que facilitan la erosión fluvial y el modelado kárstico (Niño, Gallegos y Castillo, 2008; Semarnat y Conanp, 2017). Estos procesos, combinados con la hidrología del lugar, producen escenarios naturales de primer orden para el turismo. 
Figura 1. Localización de la región turística Palenque-Cascadas de Agua Azul.

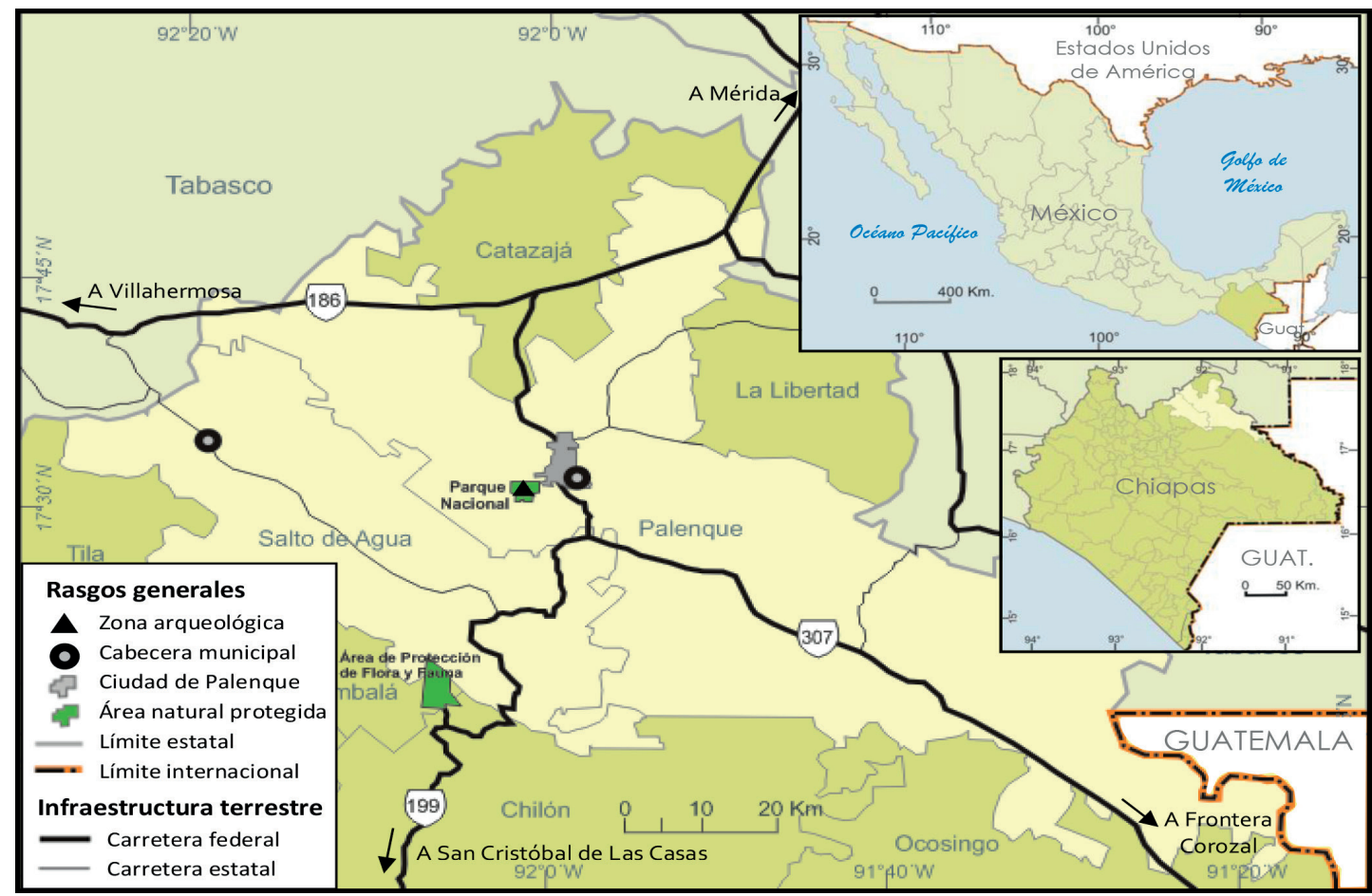

Fuente: Elaboración propia con base en datos cartográficos del INEGI.

Según la clasificación de Köppen, el clima predominante en la RPA es cálido-húmedo con lluvias todo el año (Af), con una temperatura media anual superior a los $26^{\circ} \mathrm{C}$ y la del mes más frío, rara vez desciende de $20^{\circ} \mathrm{C}$ (García, 2004). Tales condiciones garantizan un escenario tropical a lo largo del año, bien aquilatado por turistas provenientes de climas fríos, sobre todo en invierno. Por lo que respecta a la precipitación, la media anual excede de 3000 milímetros en varios puntos del área de estudio que la colocan como una de las zonas más húmedas en territorio nacional (Conagua, 2016). El $70 \%$ del volumen se reparte de mayo a octubre, lo que facilita el desplazamiento de los turistas en la época seca cuando se registran las temporadas altas para el turismo (fin de año y Semana Santa).

El área pertenece a la región hidrológica Frontera Sur, la de mayor disponibilidad y escurrimiento superficial en México (Conagua, 2016). Esto asegura profusos cuerpos de agua susceptibles de incorporarse a la actividad turística; entre ellos una red extensa de drenajes perennes y caudalosos, como los ríos Bascán, Chacamax, Nututún, Shumulhá y Tulijá, contenidos en la vertiente del Golfo de México y en la cuenca hidrológica Grijalva y Usumacinta, la más grande y caudalosa en Mesoamérica. 
La RPA forma parte del Corredor Biológico Mesoamericano que enlaza las zonas más importantes en biodiversidad del sureste mexicano y América Central. En la RPA, tal cualidad explica la presencia del Parque Nacional Palenque (1771 ha) y el Área de Protección de Flora y Fauna Cascadas de Agua Azul (2 580 ha); ambas remanentes de selvas altas y medianas perennifolias en las que subsisten, en cada una, cerca de 400 especies de plantas vasculares y 600 vertebrados terrestres, de los que $20 \%$ gozan de protección especial y 3\% son endémicos (Gómez, Pérez, Espinoza y Márquez, 2015; Semarnat y Conanp, 2017). Estos datos ilustran el potencial de tales lugares para el turismo, pero también su fragilidad ecológica.

\section{Sociedad, economía y turismo}

La población del área de estudio refleja un aumento exponencial en el último medio siglo: de 45 mil habitantes, en 1970, a más de 180 mil en la actualidad (INEGI, 2015). Tal contingente se concentra en un 65\% en Palenque; particularmente en su cabecera municipal, único conglomerado urbano en la RPA, con cerca de 50 mil habitantes. El resto de la zona estudiada se compone por más de mil localidades con menos de 2 mil 500 habitantes en las que reside el $61 \%$ de la población en Palenque y el $91 \%$ en Salto de Agua (INEGI, 2015). La mayoría de tales asentamientos conforma ejidos, cuya relevancia para esta investigación estriba en los recursos naturales que albergan para el turismo.

La composición étnica de la RPA es una de las más elevadas en México. Tanto en Palenque como en Salto de Agua, las personas que hablan alguna lengua nativa y que, además, se reconocen como indígenas corresponden al $44 \%$ y $90 \%$ de la población, en ese orden, en donde los grupos predominantes son de origen maya ch 'ol y tzeltal (INEGI, 2015). Sin embargo, otro rasgo de la RPA radica en la pobreza bajo la que subsisten el $77 \%$ de los habitantes en Palenque y el $91 \%$ en Salto de Agua (Coneval, 2016). De ahí el interés del gobierno estatal por promover el turismo, para generar empleos e infraestructura y contrarrestar tal panorama.

Aún predominan las actividades primarias en la RPA con siete de cada diez habitantes, en particular en el sector agropecuario que ocupa el $60 \%$ de la población económicamente activa (PEA) (INEGI, 2015). En agricultura, el 82\% de la superficie cosechada es de temporal y subsistencia de tres productos básicos: maíz, frijol y chile (Sagarpa, 2016). Se añaden el café, con rendimientos bajos y tecnología deficiente y, en forma creciente, la palma africana para la industria de los alimentos y cosméticos (Escobar, 2010; Gobierno del Estado de Chiapas, 2013). 
La cría de ganado bovino conforma la actividad económica preponderante en términos de extensión, valor y volumen de producción, sobre todo, en forma extensiva con productividad baja (Gobierno del Estado de Chiapas, 2013). Esta se emplaza sobre los pastizales inducidos por el desmantelamiento de la selva en más de la mitad del área, lo que contrasta con el 10\% de la superficie agrícola (Escobar, 2010; INEGI, 2017). Las actividades terciarias se restringen al núcleo urbano de Palenque. Por ser cabecera municipal y centro económico-administrativo de la Región XIII Maya, reúne una PEA terciaria más relevante (40\%) que Salto de Agua (15\%) (INEGI, 2017). En ambos casos, casi tres cuartas partes laboran en los servicios, varios concernientes al turismo, como en hoteles y restaurantes.

En relación con esta actividad económica, aunque la RPA capta los primeros flujos de turistas en los años 80, cuando se decreta la zona arqueológica de Palenque como Parque Nacional (1981) y Patrimonio de la Humanidad (1987), su despegue como destino turístico acontece en los años 90, con el levantamiento armado zapatista que, en forma sorprendente, atrae a miles de turistas nacionales y foráneos a Chiapas y motiva la habilitación de carreteras en la entidad (Coronado, 2008). Posteriormente, el gobierno mexicano promueve grandes planes de infraestructura orientados a la integración económica del sur-sureste mexicano, como Mundo Maya, Proyecto Mesoamérica, Corredor Biológico Mesoamericano y Zonas Económicas Especiales, a partir de los que se modernizan carreteras, puertos aéreos y marinos que mejoran la conectividad de Chiapas con el país e incentivan la llegada masiva de turistas nacionales y capitales ligados con el turismo, como el de hospedaje (Villafuerte, 2004; Garza y Sánchez, 2015).

En este contexto, el gobierno chiapaneco anuncia en los primeros años del siglo XXI el Centro Integralmente Planeado para el turismo (CIP) Palenque-Cascadas de Agua Azul, cuyo fin era crear el primer parque turístico eco-arqueológico de México (Fonatur, 2006). El plan maestro incluía, en más de 20 mil hectáreas, hoteles ecológicos tipo resort, miradores escénicos, teleférico, campo de golf, parque acuático y el reforzamiento de la conectividad con otros nodos turísticos regionales (Fonatur, 2012). Sin embargo, tal equipamiento no se concluyó debido a recortes presupuestales en las instituciones federales y estatales de turismo (Libert, 2019), excepto un aeropuerto, cinco kilómetros al norte de la zona arqueológica de Palenque.

En el sexenio pasado, el CIP Palenque se integró al Plan de Infraestructura 20142018, pero como uno exclusivamente cultural, igual que dos recintos arqueológicos de la Península de Yucatán: Chichen Itzá y Calakmul (SCT, 2014). Este contempló una inversión federal de 67 millones de dólares sobre 1,040 hectáreas, lo que supuso la 
continuación del proyecto original, pero con una envergadura menor con la remodelación de los accesos a la zona arqueológica y a la cabecera municipal que, en 2015, se integró al programa Pueblos Mágicos de la Secretaría de Turismo.

\section{El nodo turístico}

\subsection{Recursos}

La singularidad del área de estudio con respecto al turismo radica en la zona arqueológica de Palenque, cuyo referente más amplio lo compone la cultura maya, producto ya afianzado en el mercado turístico internacional (Sánchez y Propin, 2010). A esto se agrega que tal recinto es una de las "cunas" del Período Clásico Maya (250-900 d.C.), junto con Tikal, en Guatemala, Copan en Honduras y Calakmul, en Campeche y uno de los centros ceremoniales de mayor extensión, acervo arquitectónico, desarrollo urbano y jeroglíficos en Mesoamérica (Díaz, 2009). En 2017, Palenque captó casi un millón de turistas (920 470) que lo ubicaron como el cuarto sitio arqueológico más concurrido en el país, detrás de Teotihuacán, Chichén Itzá y Tulum (INAH, 2018). Tal contexto ilustra su peso en el mercado turístico nacional y el interés oficial de apuntalarlo como el epicentro del turismo en Chiapas (Fonatur, 2006).

Por lo que respecta al medio físico, hay tres elementos del bosque tropical de interés para el turismo: los recursos hídricos, la cubierta vegetal y la fauna. De los primeros, hay áreas someras y sin corrientes empleadas por turistas y residentes como balnearios naturales, ante el ambiente bochornoso que impera todo el año. Se suma la coloración turquesa del agua, por la disolución y combinación de materiales calcáreos con otros minerales, al menos en la época seca del año (noviembre-abril), cuando el arrastre de sedimentos es menor, lo que acrecienta su valor panorámico. El relieve escarpado origina que los ríos precipiten por taludes, de entre 5 y $30 \mathrm{~m}$ de altura; esto crea rápidos y cascadas escalonadas para natación, buceo, kayak, rafting y saltos de agua (práctica local que consiste en brincar río abajo de una poza a otra).

En cuanto a la vegetación, la RPA se publicita, por el sector público y privado, como un "paraíso tropical", "rodeada de naturaleza" o "enclavada en el corazón de la selva”, a través de eslóganes que la presentan como un escenario casi virgen donde el viajero puede "convivir", "sumergirse" o "entrar en contacto" con la naturaleza. Empero, la destrucción paulatina del ecosistema natural local por las actividades agropecuarias redujo drásticamente su extensión. Solo hay parches de selva densa en las áreas naturales protegidas (no exentas de agricultura, ganadería y desmontes clandestinos, como se constató en campo) y en algunos ejidos en los que subsisten 
armadillos, jabalíes, mapaches, ocelotes, puercoespines, tapires, tejones y tlacuaches (Semarnat y Conanp, 2017). Aunque, para resaltar el "exotismo" del lugar, la publicidad turística menciona al jaguar, tucán, guacamaya y nauyaca -una de las serpientes más venenosas del mundo-; sin embargo, no se hallaron registros confiables de su existencia. Los únicos animales fáciles de apreciar son los monos araña y saraguatos, cuyos gritos agudos suelen confundir los viajeros con los del jaguar, según se constató in situ.

Aun cuando para muchas personas la selva funge solo como marco para admirar las pirámides o concurrir a los balnearios naturales, hay tres actividades que se promocionan en tal ecosistema: uno, alojarse en medio de la selva en cabañas, palapas y tiendas de campaña, a fin de "escuchar los sonidos de la naturaleza"; dos, jungle tours diurnos y nocturnos con prácticas de senderismo, fotografía y observación y, tres, deportes de aventura como ciclismo de montaña, hiking, trekking y parapente. La espectacularidad del paisaje natural por la combinación de cascadas, ríos de color azul y vegetación es utilizada por el gobierno estatal para apuntalar a la RPA como un destino fílmico de sets de cine y televisión, así como para exhibiciones y competencias de deportes extremos, lo que se comprobó en folletos y revistas de turismo, y abona al imaginario turístico y difusión del área en el contexto mundial.

\subsection{Infraestructura de hospedaje}

La RPA registró, en 2017, 92 hoteles y 2,598 cuartos de alojamiento que representan el $10 \%$ y $13 \%$, en ese orden, de la oferta estatal y la única de esa dimensión al noreste de Chiapas (INEGI, 2017). La mitad de los establecimientos dispone solo de los servicios básicos (51\%), pero la distribución de los cuartos de hotel por categoría de estos es más uniforme: $32 \%$ de una y dos estrellas, 30\% de tres estrellas y $38 \%$ de cuatro y cinco estrellas (INEGI, 2017). Lo anterior exhibe una oferta de alojamiento heterogénea en calidad y precio, ventajosa para turistas con presupuestos distintos, desde hoteles resort o boutique de cadenas nacionales e internacionales (Best Western, Howard Johnson, Hoteles Misión y Villa Mercedes), hasta posadas, hostales, cabañas, campings y hamacas en palapas con precios de uno a cinco dólares de Estados Unidos, por noche.

\subsection{Vías de comunicación}

La RPA goza de gran conectividad con Chiapas y con el resto del país por emplazarse sobre la planicie costera, casi al nivel del mar, y su proximidad geográfica con el 
Golfo de México y la Península de Yucatán, que facilitó la construcción relativamente temprana de líneas férreas y carreteras. Las primeras se crearon en 1950, con el Ferrocarril del Sureste que enlazó la capital del país con Mérida, Yucatán, cuando "Palenque se integró al mundo" (Hardy, 2004, p.165). Aunque el tren era de carga, una vez concesionado a la empresa estadounidense Chiapas-Mayab, entre 2002 y 2005, se orientó al turismo de lujo en el segmento de Palenque a Mérida, pero se suspendió por las malas condiciones de las vías y porque la concesionaria quebró (Lastra, 1 de agosto de 2007). Este servicio pretende reanudarse en el sexenio actual con el Tren Maya mediante tres circuitos turísticos, dos de ellos partirán de Palenque: Tramo Selva (a Calakmul) y Tramo Golfo (a Chichén Itzá), lo que augura un aumento sustancial de visitantes y capitales al área de estudio.

La RPA se emplaza sobre tres carreteras vertebrales para el turismo en el sureste mexicano y en Chiapas, como se explica enseguida. La Carretera Federal 186, 28 km al norte de la zona arqueológica, la coloca a medio camino entre la Riviera Maya y la capital del país, lo que facilita visitarla, así sea de paso, cuando se viaja entre ambos lugares. La Carretera Fronteriza del Sur o 307, articula el área de estudio con los sitios arqueológicos y comunidades de la Selva Lacandona. Por ser Palenque la ciudad más cercana a ellas, a menudo se engloban en su oferta turística, a pesar de situarse a más de $100 \mathrm{~km}$ de distancia. La arteria señalada conduce también a los cruces fronterizos de El Ceibo y Frontera Corozal con la región del Petén en Guatemala (Tikal y Flores). Finalmente, al ubicarse en el extremo norte de la Carretera Federal 199, la RPA funge como puerta de ingreso o salida, hacia o desde, la Península de Yucatán. Esta vialidad es primordial para el turismo en Chiapas, ya que enlaza las dos localidades con más turistas internacionales: Palenque y San Cristóbal de Las Casas, entre las que, en diciembre de 2019, el gobierno estatal aprobó la construcción de la "Carretera de las Culturas" para acortar y mejorar el traslado de viajeros y residentes, a concluirse en un lustro. La articulación terrestre de la RPA se completa con una red de extensa de transportes (autobuses, colectivos y taxis) que la enlaza con las ciudades y destinos turísticos del centro y sureste mexicano, y la Península de Yucatán. Estas rutas parten de la terminal de autobuses ADO y varias compañías locales de segunda categoría instaladas en la cabecera de Palenque.

En cuanto a los enlaces aéreos, la inauguración, en 2014, del aeropuerto internacional de Palenque permite, por vez primera, la conexión directa con la Ciudad de México, mediante dos vuelos semanales de la compañía Interjet. Además, con el anuncio del Tren Maya, la hemerografía local reporta el interés del gobierno chiapaneco por abrir nuevas rutas a Oaxaca, Cancún y Tikal, en el mediano plazo. Con todo, 
los pocos vínculos aéreos de la RPA se compensan con el aeropuerto internacional de Villahermosa, Tabasco, situado a 135 kilómetros de distancia (a una hora y media) de Palenque con servicios ida y vuelta a esta ciudad, cada 30 minutos, en vans, taxis y autobuses, y que cuenta con vuelos a los núcleos urbanos más importantes del territorio mexicano y a Houston, en Texas.

\section{Arreglo territorial de la oferta turística}

Con base en los recorridos en campo se identificaron tres escenarios para la promoción del turismo en la RPA que se examinan a continuación:

6.1 Carretera Palenque-"Ruinas". Se revela como el espacio más dinámico para el turismo por su vecindad con la zona arqueológica. Se extiende como un corredor paralelo a la Carretera a las Ruinas donde se contabilizó una decena de cafeterías y restaurantes y 24 alojamientos; una cuarta parte son de los más exclusivos del lugar, como Villa Mercedes, Chan Ká Resort, Axkán Arte y Villas Kin-Há; el resto posee instalaciones de menor tamaño y calidad como cabañas, campings y trailer parks. El atractivo del lugar para el turismo radica también de situarse en los márgenes del Parque Nacional con arroyos, pozas de agua, cascadas y senderos interpretativos, como el de Motiepá que exhibe vestigios arqueológicos parcialmente cubiertos por la vegetación. El corredor se distingue por el estilo "rústico" ó "ecológico" de los alojamientos con servicios de terapias con medicina tradicional (temazcal, espacios de meditación, yoga y relajación), así como elementos hippies (tatuajes, palapas con mantas y posters zapatistas o revolucionarios), bohemios (música en vivo), esotéricos (lectura de cartas y simbología maya), científicos (proyección de documentales y conferencias) y la vida nocturna en plena selva. Estos ingredientes son particularmente llamativos para el turista internacional que hace del lugar su resguardo principal en la región y, también, constituyen una especie de escape para tabasqueños y chiapanecos los fines de semana, según refirieron los empleados de hoteles. El lugar emblemático del corredor es "El Panchán", antes un racho ganadero con todos los elementos antes señalados, al que Lonely Planet califica como el "epicentro del turismo alternativo en Palenque, hogar de trotamundos y artistas bohemios" (Beth, 2010, p. 755). En un esfuerzo por diversificar la oferta turística del corredor se crearon dos parques temáticos con inversión privada, basados en la conservación de la selva, la educación ambiental y la recreación: Ecoparque Aluxes y Ecomundo que gozan de gran popularidad entre 
turistas y residentes, por lo que se afianzarán como escenarios complementarios a la zona arqueológica.

6.2. Cabecera municipal. A pesar de que la cabecera de Palenque cuenta con una oferta restringida para el turismo -Casa de Cultura, Iglesia de Santo Domingo, Museo del Textil Lak Puj Kul y Plaza del Artesano -, su importancia para este sector reside en los servicios que dispone: hospedaje ( $80 \%$ de los hoteles en la RPA), alimentación (80 negocios con categoría turística), transporte (terminales de autobuses, colectivos y taxis) y otros complementarios como bancos, minisupers y farmacias. Este equipamiento es prácticamente inexistente en el resto de la Región Selva en Chiapas, lo que torna a la ciudad en su mejor centro de apoyo turístico (Ayuntamiento de Palenque, 2007). El grueso de los servicios está confinado en tres áreas que acaparan las inversiones, así como la atención y demanda de los turistas (figuras 2 a y 2 b): 1 . Corredor inter-urbano Pakal-Ná-Palenque: corresponde al segmento de la Carretera Federal 199, entre el aeropuerto y la terminal de autobuses ADO, asiento de grandes hoteles de tres y cuatro estrellas. 2. Avenida Juárez y Parque Central: contienen la mayor dinámica comercial en la ciudad con numerosos negocios para la población local, así como hoteles, bancos, restaurantes, minisupers, transportadoras turísticas y terminales de taxis, colectivos y autobuses. Esta área se remodeló a causa de la inscripción de la cabecera de Palenque a los Pueblos Mágicos de México, con lo que se intenta atraer más visitantes, según los oficiales de turismo entrevistados. 3. La Cañada: es la única zona verde en la ciudad emplazada en un reducto de selva reforestada; posee un concepto ecoturístico, similar al de la Carretera a las Ruinas, con cafeterías, restaurantes y hoteles de tres y cuatro estrellas, calles empedradas y buen alumbrado, por lo que es el lugar con más turistas internacionales.

6.3. Ecoturismo. Este segmento se expandió en Chiapas, desde los años 90, al grado de que el gobierno estatal promociona hoy a la entidad como el "paraíso del ecoturismo en México", por ser la segunda entidad federativa con más biodiversidad y la primera en áreas naturales protegidas (Conabio, 2013). En la RPA se identificaron 14 centros ecoturísticos mediante el trabajo de campo, páginas web, folletos, revistas y mapas de turismo. Para efectos de esta investigación son lugares en el espacio rural que cuentan con uno o varios recursos del bosque tropical de interés para el turismo (ríos, lagos, pozas de agua, cascadas, zonas de vegetación y fauna) y algunos servicios de atención al turista. 
Figura 2a. Palenque: arreglo territorial de la oferta turística

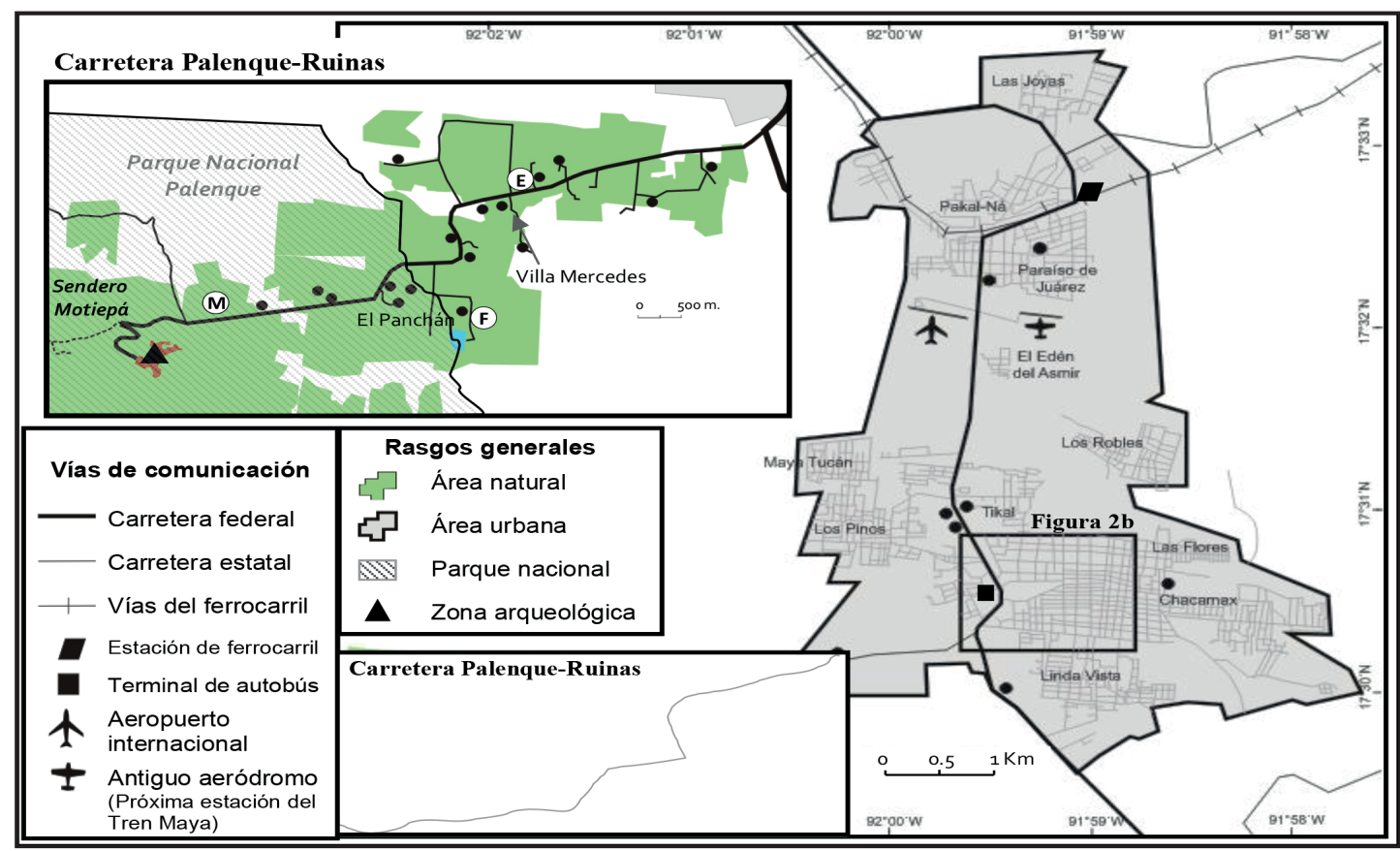

Fuente: Elaboración propia con base en trabajo de campo.

Figura 2b. Cabecera municipal de Palenque: La Cañada y Avenida Juárez-Parque Central

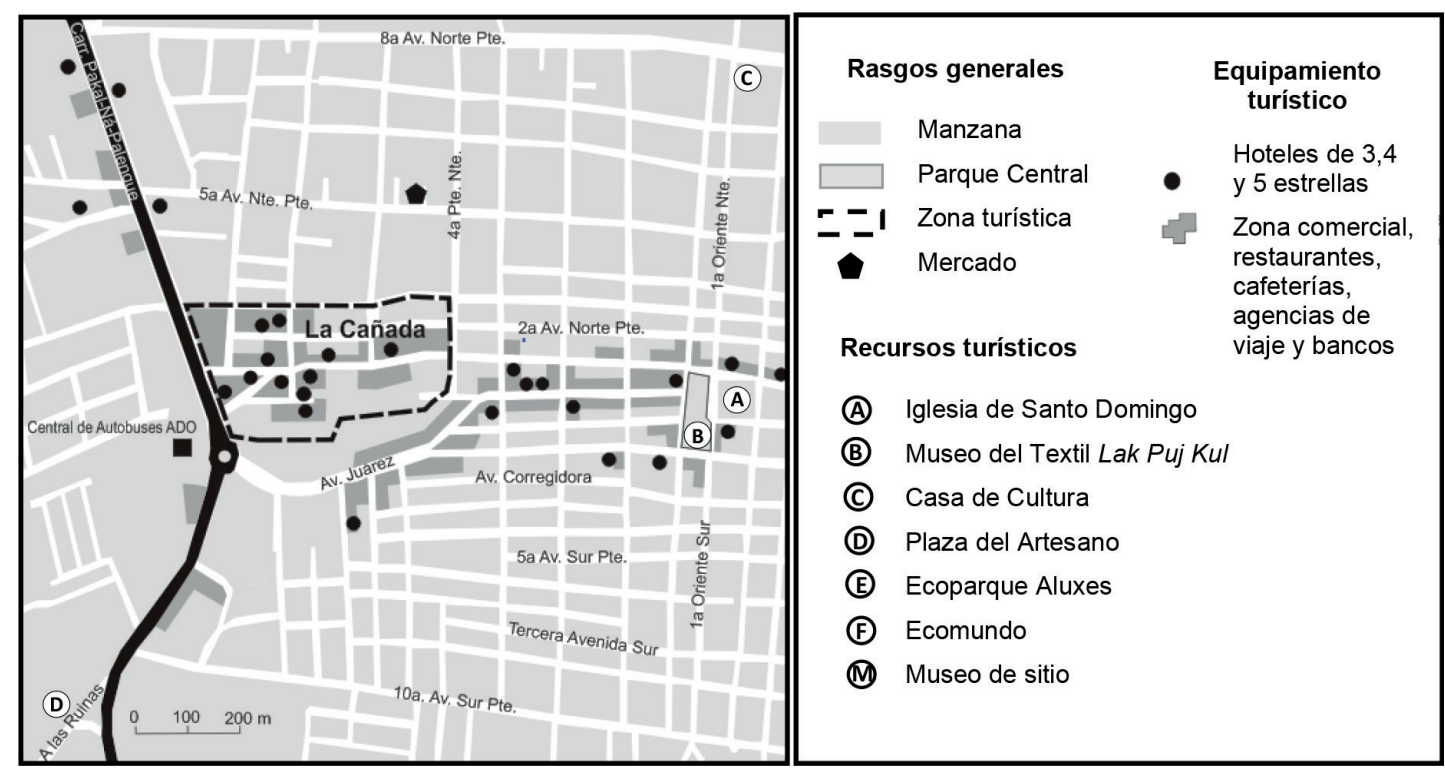

Fuente: Elaboración propia con base en trabajo de campo. 
La mayoría de los centros ecoturísticos en el área de estudio (12) pertenecen a comunidades indígenas ch 'ol y tzeltal y se localizan en ejidos donde un sector al interior de ellos se dedica al turismo, mientras que solo dos se ubican en propiedades privadas (Parador Valle Escondido y Kan Kan Há). Las actividades que promocionan van desde natación y observación de flora y fauna hasta deportes extremos, como kayak y rafting, junto con el conocimiento de las tradiciones locales. Con estas actividades el gobierno municipal y estatal buscan revertir la pobreza de sus propietarios y hacer un uso sostenible de los recursos naturales (Ávila-Romero, 2015), así como diversificar la oferta turística de la RPA más allá de la zona arqueológica de Palenque, según las autoridades de turismo entrevistadas: "mientras esta se vende sola, los centros ecoturísticos sirven para prolongar la estancia de los visitantes a ese recinto cultural que se registra todo el año y en ocasiones dura unas horas". Sin embargo, se halló un espectro amplio de tales lugares en función de ocho atributos con los que se elaboró la figura 3 y que son: 1. Acceso pavimentado, 2. Capacitación, 3. Guías y renta de equipo, 4. Restaurante, 5. Cabañas, 6. Transportación, 7. Promoción oficial y 8. Referencia en mapas turísticos.

En una posición privilegiada están Cascadas de Agua Azul y Misol-Há que cuentan con todo lo anterior, desde buena accesibilidad por la carretera federal 199 y equipamiento, hasta colaboración con agencias de viaje. Ambos lugares registran cerca de tres mil excursionistas al día en temporadas altas o fines de semana y, al año, alrededor de 400 mil, de acuerdo con los comisariados ejidales. Esto los coloca entre los sitios turísticos más visitados en Chiapas, cuyos paisajes usa el gobierno del estado para publicitar el ecoturismo en la entidad y que en varias páginas de internet aparecen en el top ten de las cascadas más bellas en México. Incluso, en Agua Azul se planeaba habilitar un parque acuático, similar a Xcaret en Cancún, con aldeas mayas, jardín botánico, campo de golf, hoteles resort, miradores y zoológico (Fonatur, 2012). Tanto Misol-Há como Agua Azul se incluyen en la mayoría de los tours para la zona arqueológica de Palenque, mientras esta se recorre por la mañana, los segundos se promocionan para "tomar un baño" o "refrescarse" después, al medio día, en las horas de más calor. 
Figura 3. Centros ecoturísticos identificados en la región Palenque-Cascadas de Agua Azul, Chiapas.

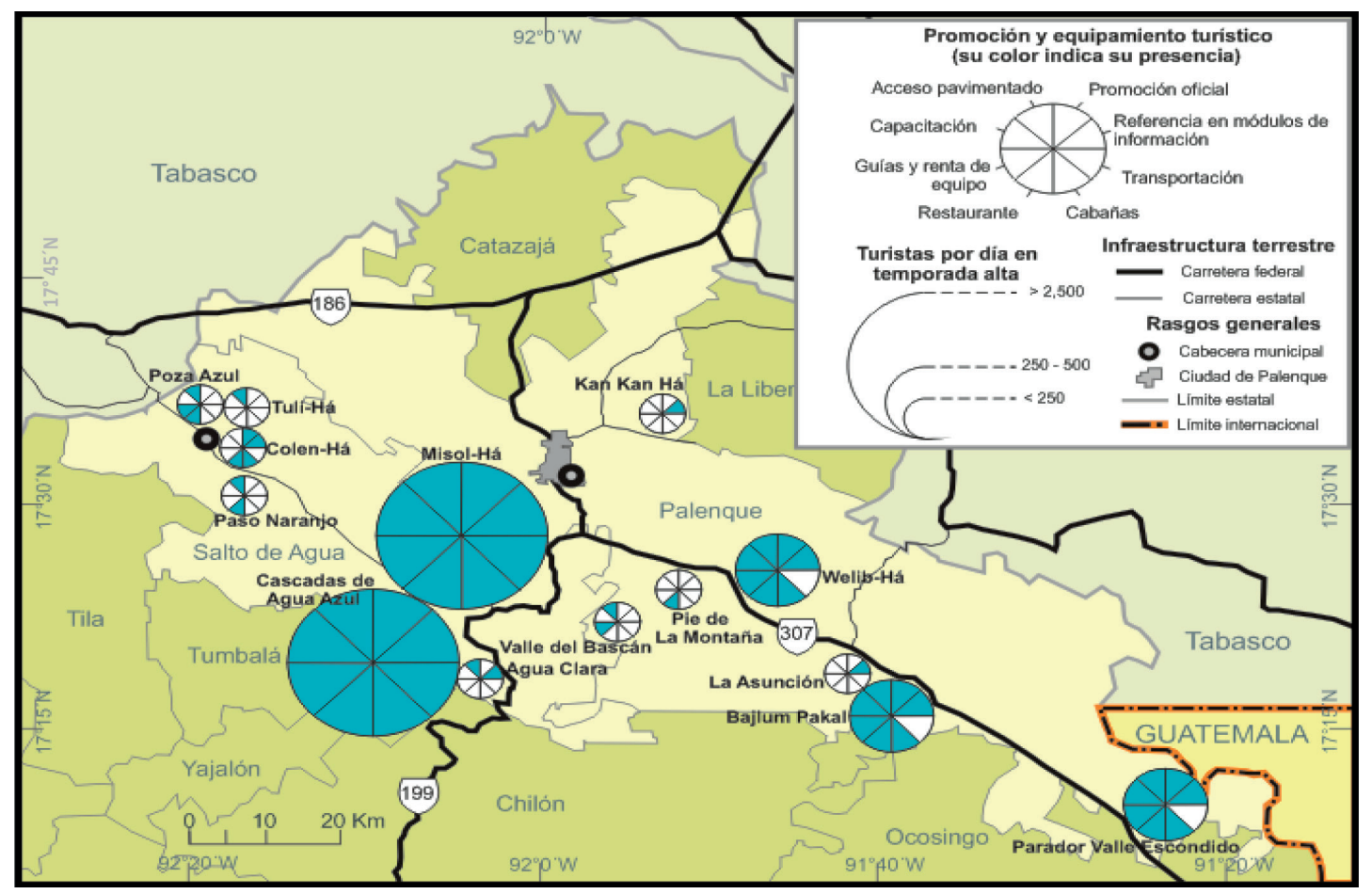

Fuente: Elaboración propia con base en trabajo de campo.

En una posición intermedia se ubican Welib-Há, Colen-Há, Bajlum Pakal y Parador Vallescondido. Se trata de lugares con, al menos, cuatro atributos para el turismo de los ocho aquí considerados, incluso, los tres primeros gozan de certificación en alojamiento y alimentación por la Secretaría de Turismo. Sin embargo, adolecen de una cooperación con las transportadoras turísticas, lo que los excluye de los itinerarios establecidos por esas compañías, debido a la falta de interés de estas, a su poca accesibilidad o a que no son convenientes para los ejidatarios por la cuota alta que exigen por turista, según el comisariado de Welib-Há. La única forma de visitarlos es por vehículo particular, taxis o colectivos desde la cabecera de Palenque.

Al otro lado del espectro, se hallaron ocho centros ecoturísticos con tres o menos ventajas para la actividad turística. Aún cuando tienen referencia en mapas, carecen de promoción oficial e, incluso, instalaciones básicas para el turismo. Por esta razón, pasan desapercibidos para el grueso de las personas que arriba a Palenque, a pesar de tener paisajes similares a los de Misol-Há y Cascadas de Agua Azul. Con todo, su atractivo descansa en su aislamiento geográfico que abona al imaginario de los visi- 
tantes en torno a la selva chiapaneca como un escenario inmaculado y apacible. Esto fue indicado por los encuestados y en TripAdvisor donde se les describe como "paraísos exóticos", "excelentes para la meditación y el descanso" y "alejados del bullicio". Aunque también la falta de seguridad, equipo y guías certificados representa un riesgo para el turista. En campo se observó que estos lugares son visitados, en forma mayoritaria, por mochileros o voluntarios de organizaciones no gubernamentales (ONG) y por la población local que ahí concurre los fines de semana y en períodos vacacionales.

\section{Turistas: patrón territorial de desplazamiento}

En 2017, la RPA recibió 515 mil turistas y ocupó la tercera posición entre los destinos turísticos chiapanecos, después de San Cristóbal de Las Casas y Tuxtla Gutiérrez, y la primera por los de origen extranjero con 93 mil (18\%) (Sectur, 2018). En este contexto, las encuestas a visitantes revelaron que el $90 \%$ de estos últimos provino de tres regiones: Europa Occidental (50\%), América Latina (22\%) y América del Norte (18\%), y 32 países diferentes, lo que corrobora el alcance de la RPA en el mercado turístico internacional (figura 4). En el plano nacional, se hallaron viajeros de 25 entidades federativas, de los que tres cuartas partes residían en diez núcleos urbanos del centro-occidente del país, a mil y mil 500 kilómetros de distancia del área de estudio, como Ciudad de México, Guadalajara, Guanajuato, Morelia y Toluca. El resto eran personas del sureste mexicano (20\%), la frontera norte (17\%) y Chiapas (3\%) (figura 5).

Las "ruinas" o "pirámides" de Palenque fueron para el $67 \%$ de los encuestados el motivo principal para visitar el área de estudio, a las que calificaron como "únicas", "irrepetibles" o "majestuosas" y a las que regresarían y recomendarían. Si bien el pasiaje natural (selva, cascadas o ríos) se citó en primer lugar por una cuarta parte de los turistas (24\%), su cercanía y originalidad representó para la mayoría de los encuestados "un complemento excepcional a su viaje", "de gran belleza" o un "marco ideal a la arqueología". 
Figura 4. RPA: Procedencia geográfica de los turistas internacionales encuestados

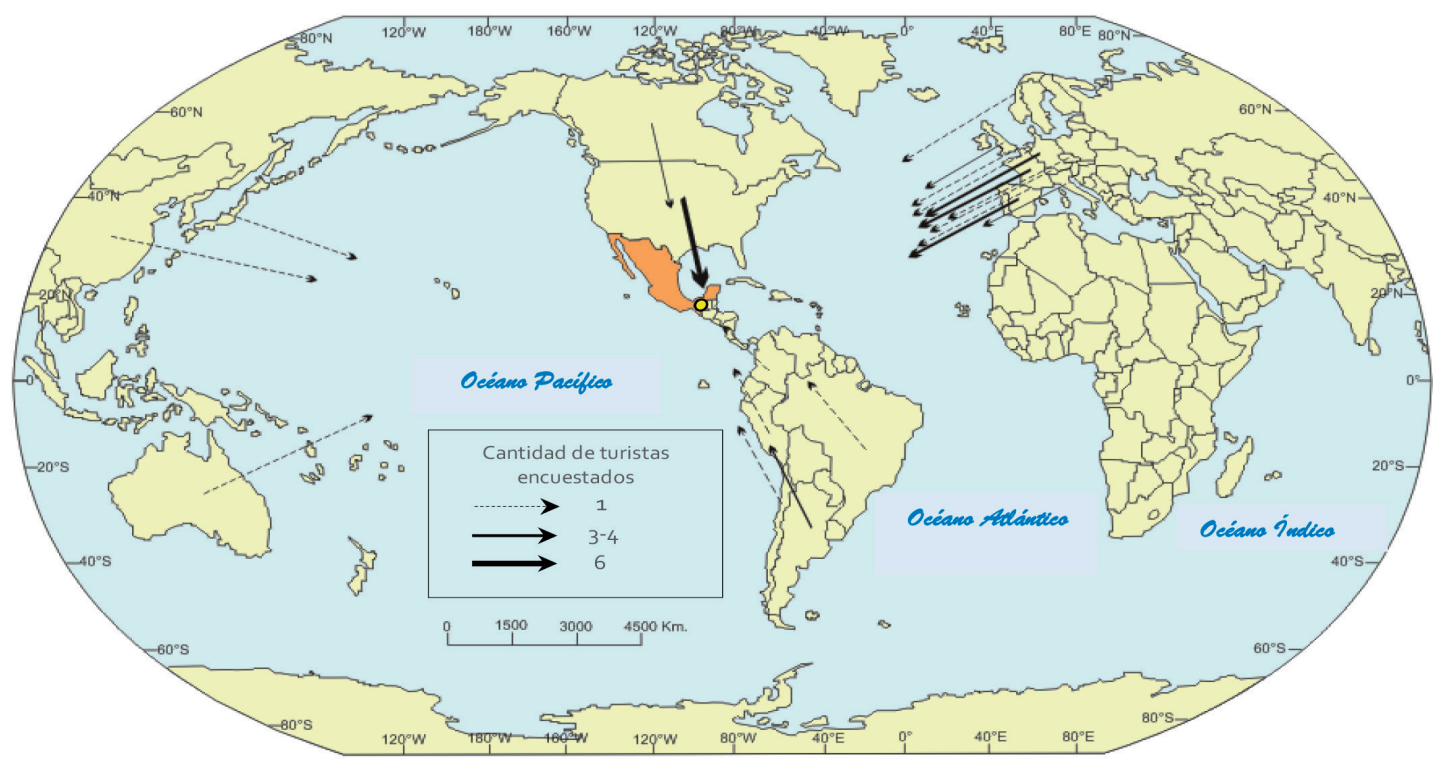

Fuente: Elaboración propia con base en trabajo de campo.

Figura 5. RPA: procedencia geográfica de los turistas nacionales encuestados

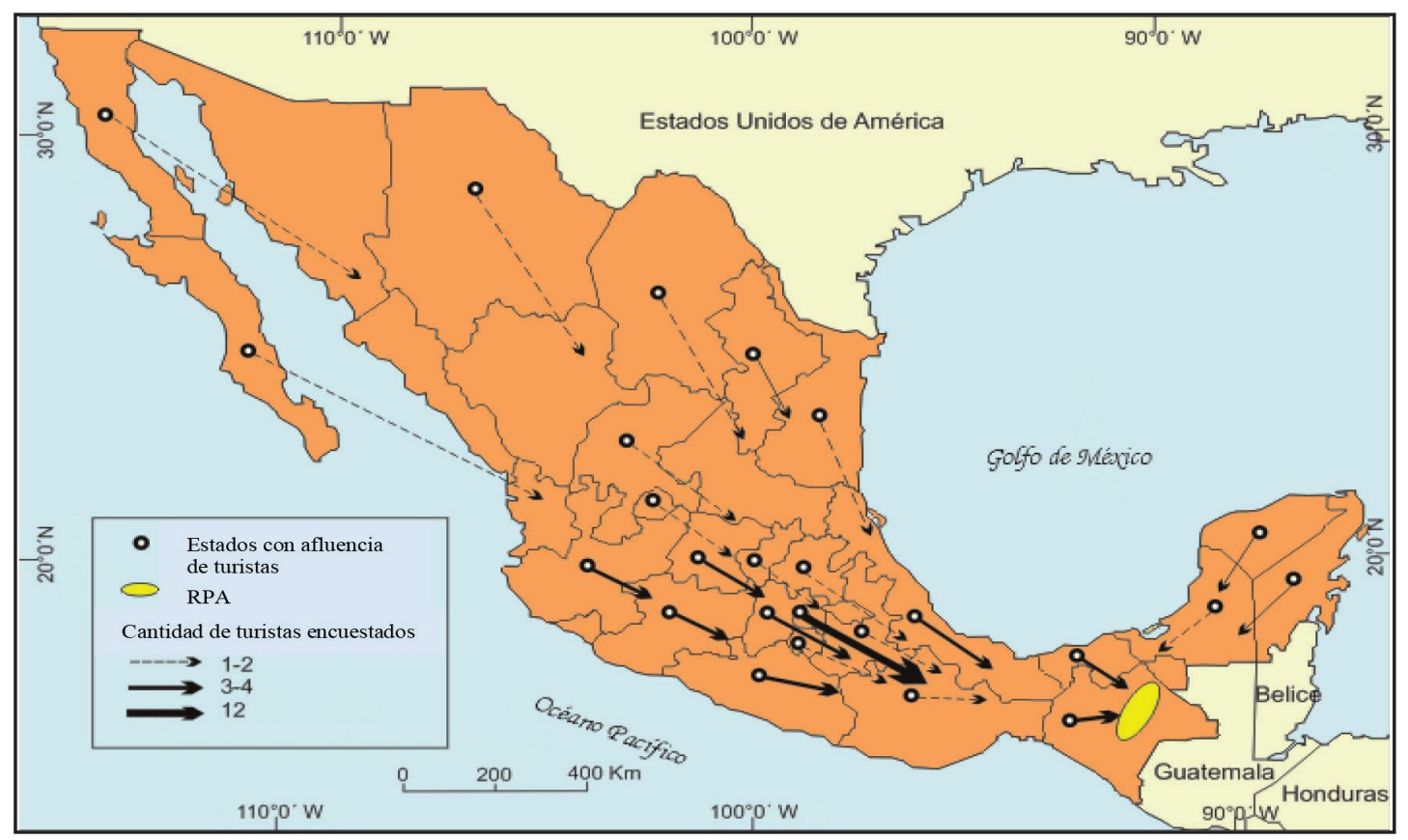

Fuente: Elaboración propia con base en trabajo de campo. 
Asimismo, el $76 \%$ de los encuestados de origen nacional y todos los extranjeros visitaron, antes o después de la RPA, otros puntos de interés en el Mundo Maya. En consonancia con esta situación, el medio de transporte de todos los encuestados para acceder o salir del área de estudio fue terrestre, lo que evidencia la baja demanda del aeropuerto de Palenque. La explicación subyace en que la RPA conformó, para el $68 \%$ de ellos, un destino turístico intermedio en su itinerario de viaje por el sureste mexicano y América Central, que disponen de aeropuertos mejor interconectados con México y otros países; entre ellos, el de Villahermosa, Tabasco, por el que llegó un 18\% de los encuestados de origen nacional.

El contingente más relevante de turistas arribó a la RPA por cuenta propia en autobús (39\%) y en transportes de agencias de viaje (47\%). De las segundas hubo tres tipos: las turoperadoras extranjeras (15\%), las compañías nacionales (8\%) y las locales que operan desde otros sitios en Chiapas (24\%). Solo el $14 \%$ de las personas accedieron en vehículo particular y residían en el territorio chiapaneco o en entidades vecinas, lo que se asocia con la cercanía y el conocimiento de las carreteras. Al interior del área de estudio, se detectó que tres cuartas partes de los turistas (74\%) empleó las transportadoras turísticas locales y las de los hoteles para ir de la zona arqueológica a Misol-Há y Cascadas de Agua Azul. Esto tiene que ver con el precio relativamente accesible de los tours, entre 30 y 50 dólares estadounidenses, y la facilidad de contratarlos en hoteles, restaurantes, terminales de transporte y sobre la Avenida Juárez. Se adicionan factores técnicos y sociales que abonan al uso extendido de tales compañías entre los viajeros, como el mal estado de las carreteras, la falta de gasolineras y la inseguridad; esta incluye bloqueos carreteros, tráfico de drogas, conflictos intracomunitarios y robos que alcanzan difusión internacional, especialmente cuando afectan a extranjeros, como entre 2017 y 2020 , a turistas alemanes, coreanos, ingleses y polacos, según reportes de la prensa local y nacional, lo que merma el desarrollo de la actividad turística.

Con relación al tiempo de permanencia en la RPA, el $54 \%$ de los encuestados se quedó dos días, una tercera parte menos de 24 horas (29\%) y el $17 \%$ tres días o más. Esto concuerda con cifras oficiales en las que la estadía promedio en Palenque apenas supera una noche por turista (1.07). De acuerdo con el trabajo de campo, hay dos razones de esto: una es la promoción de solo cuatro sitios: zona arqueológica y Parque Nacional Palenque, Misol-Há y Cascadas de Agua Azul. No sorprende así que el $77 \%$ de los ecuestados limitó su visita a estos, por cuenta propia o en tours. La otra razón es la falta de espacios y eventos de entretenimiento y culturales más allá del ingrediente arqueológico. 
Finalmente, con base en las encuestas se identificaron cuatro tipos de turistas en el área de estudio con los siguientes perfiles: a. Jubilados extranjeros: eran de origen europeo que contrataron los tours en sus países de origen y que arribaron al país vía aérea, por la Ciudad de México o Cancún. Entre esos puntos recorrieron, por autobús, varias localidades del sursureste del país y la Península de Yucatán en viajes de una semana a un mes, en grupos de 50 personas o más. Si bien permanecieron una noche o menos en la RPA, realizaron un gasto importante en hospedaje y alimentación, de cerca de 100 dólares estadounidenses por día. La mayoría se alojó en hoteles de cuatro y cinco estrellas en la Carretera a las "Ruinas", para visitar únicamente la zona arqueológica al día siguiente. Estos turistas son de los más afectados por los asaltos en la Carretera Federal 199.

b. Mochileros extranjeros: jóvenes europeos que recorrieron por cuenta propia, solos o con amigos, varias entidades del país e, incluso, otras naciones de América Latina, en períodos de un mes a seis meses. Además de viajar por placer, algunos trabajaban en ONG en Chiapas, agrupaciones zapatistas y vendían artesanías para costear su viaje. El grueso se hospedó con amigos, hostales, pensiones, campings o en hamacas dentro palapas sobre la Carretera a las "Ruinas". También, acudieron a fondas y cafeterías y usaron el transporte público (colectivos, autobuses y taxis), o bien, las operadoras turísticas locales para dirigirse a los centros ecoturísticos.

c. Turista nacional 1: corresponde al grueso de los visitantes nacionales que viajó en vacaciones de Semana Santa, verano, fin de año y en días feriados, con amigos y familiares, por cuenta propia o touroperadoras nacionales, cuyo itinerario abarcó otras localidades en el sureste mexicano. La mayoría se alojó en hoteles de dos, tres y cuatro estrellas en la cabecera de Palenque, La Cañada y, en menor medida, en la Carretera a las "Ruinas".

d. Turista nacional 2: personas de otros municipios chiapanecos y Tabasco que se desplazaron en vehículo particular con familiares o amigos. Estos individuos llegaron los fines de semana y en días feriados. Se caracterizaron por visitar más restaurantes, espectáculos nocturnos en hoteles (sobre la Carretera a las Ruinas) y parques temáticos (Aluxes y Ecomundo), sin necesariamente entrar a la zona arqueológica, a la que antes ya habían visitado.

e. Turista nacional 3: se refiere a las personas que arribaron por motivos científicos, académicos o de trabajo, como a las mesas redondas de Palenque y a otros eventos, públicos o privados, relacionados con la arqueología, con estancias mayores a dos días y un consumo superior a 50 dólares en alimentación y hospedaje. 


\section{Estructura territorial del turismo en la RPA}

Con base en los apartados anteriores se elaboró el mapa final que sintetiza la información contenida en esta investigación (figura 6). En él se corrobora que el nodo en torno al que gravita la actividad turística en la RPA es la zona arqueológica de Palenque. Allí inicia o concluye el itinerario de los turistas y hacia ella están orientados los servicios de hospedaje y vías de acceso principales. Su trascendencia prehispánica aporta los elementos valorizados hoy por el turismo que, aunada al decreto como Patrimonio de la Humanidad por la Unesco y a una intensa inversión, pública y privada, en promoción y equipamiento turístico, la afianzan como un punto ineludible en la Ruta Maya, que año con año recorren miles de turistas nacionales y extranjeros.

Respecto a la selva, a pesar de estar sometida a una gran perturbación ecológica, conserva elementos hídricos, arbóreos y faunísticos de gran singularidad, que completan la visita a la zona arqueológica de Palenque. La mayoría de tales recursos está confinada a las áreas naturales protegidas, pero también en 14 centros ecoturísticos, casi todos indígenas, en los que se asienta en diversos grados la economía turística. Tres son los nichos en que estos lugares basan su apuesta para el turismo: ecoturismo, turismo de aventura y turismo comunitario con actividades acuáticas y en la selva de tipo contemplativo, deportivo y cultural por el contacto con los grupos autóctonos, de gran demanda a nivel mundial.

Más allá de su oferta turística, otro factor que explica el crecimiento y dinámica espacial del turismo en la RPA es su posición geográfica y conectividad terrestre con la Selva Lacandona, la Península de Yucatán y Guatemala. Tales ventajas la colocan como un sitio de enlace hacia tales regiones, que se refuerza por los servicios de alimentación, alojamiento, transporte y otros suplementarios en la ciudad de Palenque. Esto parece ser el motivo por el que el área de estudio es la única del estado incluida en una cuarta parte de los tours y paquetes de viaje a la Ruta Maya, examinados para este estudio. Además, la articulación terrestre de la RPA con otros circuitos turísticos en Chiapas y fuera del estado sirvió para proyectarla, a principios de siglo, como un centro de distribución del turismo en Chiapas (Fonatur, 2006 y 2012). Este atributo crecerá con la construcción de nuevos canales de comunicación aérea (a Oaxaca, Cancún y Tikal), ferroviarios (a Mérida y Chetumal con el Tren Maya) y carreteros (autopista a San Cristóbal de Las Casas), en el corto y mediano plazos (Mariscal, 26 de diciembre de 2019). 
Figura 6. Estructura territorial del turismo en la región

Palenque-Cascadas de Agua Azul, Chiapas.

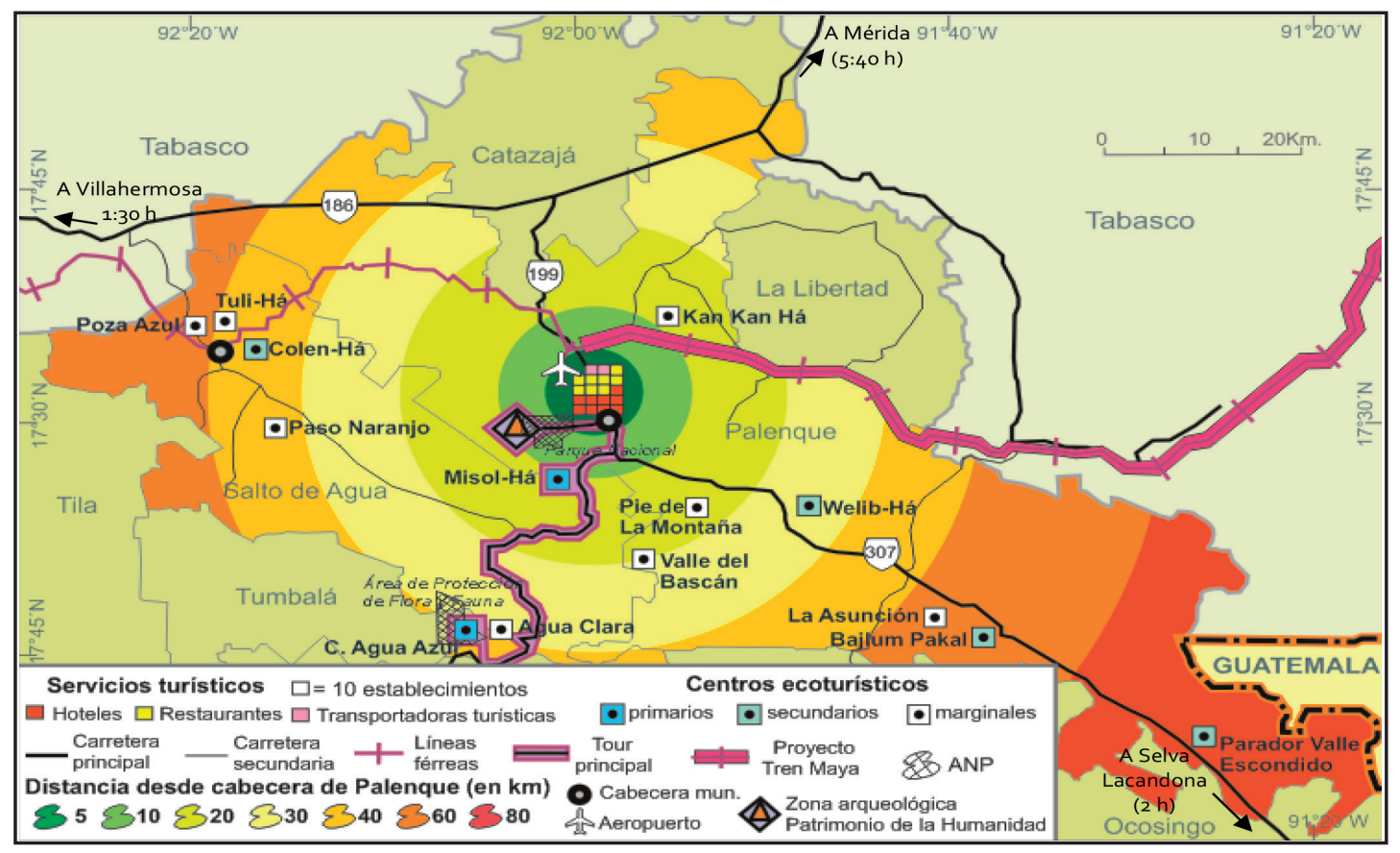

Fuente: Elaboración propia con base en trabajo de campo.

A pesar de este escenario propicio para el crecimiento del turismo, esta actividad sigue un patrón espacial puntual en torno al sitio arqueológico y a dos centros ecoturísticos: Misol-Há y Cascadas de Agua Azul, los tres emplazados sobre la Carretera Federal 199. La visita consecutiva a ellos (por lo general, tres horas en el primero, 30 minutos en el segundo y tres horas en el tercero) es prácticamente el único tour, en internet e in situ, para el área de estudio, del que casi el $80 \%$ de los entrevistados "escapó" a otros sitios turísticos. Se observó que a esto contribuye el que las agencias de viaje locales y foráneas, en vez de ofrecer más recorridos al interior de la RPA, trasladan directamente a los turistas a la estación de autobuses en Palenque para seguir en la Ruta Maya o a San Cristóbal de Las Casas, donde el 38\% de los encuestados prefirieron pernoctar por su mayor oferta cultural, de entretenimiento y servicios, según lo referido por ellos mismos.

El contexto anterior da lugar a la saturación de personas en los tres sitios antes aludidos, en particular los fines de semana y en temporadas altas cuando reportan casi tres mil en un día. Por ejemplo, la Carretera a las "Ruinas" se congestiona de transportes turísticos y vehículos particulares que tardan hasta cuatro horas para entrar al sitio prehispánico, de acuerdo con la prensa local, y que se agrava con el cobro de entrada 
al Parque Nacional, a cargo de la Comisión Nacional de Áreas Naturales Protegidas (Conanp). Esto genera el encono de turistas, delegados y transportistas del sector turístico, ya que el grueso de los viajeros no visita propiamente el área natural, solo la cruza para acceder a la zona arqueológica. Para resolver este problema, se ha planteado por parte del sector público y privado, según los delegados de Turismo Regional, la creación de un solo pago para el INAH y la Conanp, así como la instalación de un teleférico, pero no se han concretado por falta de presupuesto y de acuerdos institucionales.

En Misol-Há y Cascadas de Agua Azul el problema aumenta con los puestos de comida, souvenirs y artesanías de los ejidatarios, sobre todo en el segundo, donde se contaron más de 300. Esto desvanece la naturaleza prístina con la que se les publicita y genera animadversión entre algunos turistas. De hecho, una quinta parte de los encuestados calificó al segundo recinto como un "tianguis feo y sucio", "demasiado turístico" y "sobrevalorado", al que "dudosamente regresarían". Se agregan conflictos intracomunitarios por el acceso a ambos centros ecoturísticos, ya que los ejidos circundantes instalan casetas de cobro para beneficiarse también del cruce de turistas. Esto, además de ocasionar la molestia de algunos visitantes, transportistas y delegados de turismo, crea una tensión social entre los propietarios de los centros ecoturísticos y sus vecinos, lo que generó enfrentamientos violentos en Cascadas de Agua Azul, entre 2007 y 2011, en los que intervino el gobierno estatal. En la actualidad, la situación se tiene relativamente resuelta con un cobro doble mínimo en Misol-Há (0.25 USD) y una sola caseta de cobro en Agua Azul, bajo la Conanp, cuyo monto se divide a la mitad entre el centro ecoturístico y el ejido vecino de Bachajón.

De esta manera, la concentración espacial del turismo entorpece su encadenamiento productivo con la economía local. En la ciudad de Palenque, solo las áreas en torno a la cabecera, la zona arqueológica y el aeropuerto poseen un equipamiento urbano y turístico en condiciones óptimas, pero afuera proliferan los asentamientos irregulares por el crecimiento demográfico acelerado de los últimos años. En el ámbito rural aún predominan las actividades agropecuarias tradicionales y extensivas con las que el turismo compite por el territorio y los recursos. En este contexto subsisten 14 centros ecoturísticos entre los que se aprecian diferencias sustanciales en cuanto a equipamiento, accesibilidad y promoción. Solo Cascadas de Agua Azul y Misol-Há, catalogados aquí como centros ecoturísticos primarios, reciben un flujo sostenido de visitantes a lo largo del año, mientras que el grueso de los centros secundarios y marginales apenas tienen accesos y referencia en mapas o sobre las carreteras. Esto condiciona su participación en la dinámica turística y, lejos de conformar un producto integral que atraiga más visitantes y prolongue su estadía, limita la distribución equitativa de los beneficios que aportan. 


\section{Conclusiones}

La estructura territorial del turismo en la RPA goza de dos espacios bien diferenciados para la promoción de esta actividad: la zona arqueológica maya y el bosque tropical Iluvioso. La primera engarza el imaginario de los viajeros que allí arriban y organiza la dinámica turística espacial, desde la infraestructura hotelera y carretera, hasta el desplazamiento de los turistas. En forma paralela, el área dispone de un patrimonio natural destacado por situarse en el límite de dos grandes regiones geomorfológicas, su latitud tropical y cercanía con el Golfo de México. Esto redunda en dos situaciones favorables para el turismo: la primera es un volumen extraordinario de agua que, por el desnivel del terreno y los procesos kársticos, forma caídas escalonadas de gran espectacularidad, algunas emblemas del turismo en Chiapas, como Misol-Há y Cascadas de Agua Azul. La otra circunstancia es una biodiversidad alta del bosque tropical, cuya accesibilidad y equipamiento las tornan en una de las formas más fáciles de internarse en la selva chiapaneca.

El hecho de que el RPA esté plenamente integrada en el Mundo Maya brinda enormes ventajas al turismo por la promoción internacional y los proyectos de infraestructura y turísticos de carácter federal, lo que facilita la interconexión entre los recursos y el desplazamiento de los viajeros. Esto es de particular trascendencia para el área de estudio por su localización a la entrada de la Península de Yucatán, articulación con las comunidades lacandonas más conocidas y Guatemala. Tal cualidad hace que la RPA actúe como nodo estratégico del turismo dentro y fuera de Chiapas, por la que se volvió receptora de importantes planes para esta actividad, desde el CIP Palenque-Cascadas de Agua Azul, a inicios de siglo, hasta el Tren Maya en el actual sexenio presidencial, a concluir en 2024.

Sin embargo, frente a ese panorama ventajoso para el turismo en la RPA, prevalece un patrón espacial heterogéneo a su interior, con una fuerte desarticulación entre los recursos turísticos. Tal proceso subyace a la implantación de un esquema masivo y selectivo en el que pocos recintos acaparan las inversiones, públicas y privadas, así como los flujos de turistas. En el municipio de Palenque son perímetros bien acotados entre la zona arqueológica y el aeropuerto internacional. Se agrega la cabecera municipal que, pese a contar con una oferta hotelera importante y el título de Pueblo Mágico por la Sectur, carece de una imagen atractiva para esta actividad y está lejos de captar un volumen similar de visitantes al de su competidor más cercano: San Cristóbal de Las Casas, ciudad colonial en la que muchos turistas prefieren pernoctar por 
su mayor equipamiento de recursos y servicios turísticos y que ejerce un papel central en la dinámica del turismo chiapaneco.

En el espacio rural, solo dos de 14 centros ecoturísticos tienen una entrada continua de viajeros: Cascadas de Agua Azul y Misol-Há englobados en la oferta turística del área con el sitio arqueológico. Tal panorama conduce a la masificación de tales escenarios frente al abandono de la mayoría, incluso con rasgos igualmente singulares, pero incapaces de insertarse en la dinámica turística actual, amén de su limitada promoción e infraestructura. En correspondencia, es contradictorio que, pese al interés oficial y privado de prolongar la estancia de los turistas y diversificar la oferta turística de la región estudiada, la publicidad y los tours para desplazarse a su interior se limiten a esos sitios.

El contexto anterior tiene repercusiones socioeconómicas negativas como la supremacía en la región de una economía de subsistencia y la participación limitada de la población local en el turismo, particularmente de los indígenas, el sector dominante, que se dedica a la venta informal de artesanías, alimentos y bebidas o que se emplean en puestos de baja cualificación en hoteles y restaurantes. Se adicionan fuertes desequilibrios entre las comunidades rurales por el ingreso de turistas, donde el éxito relativo de unas, en términos económicos, contrasta con la pobreza de la mayoría, lo que justificaría profundizar en futuras investigaciones.

Pese a lo anterior, la RPA podría contender aún, desde una posición ventajosa, con otros destinos turísticos del sureste mexicano, por la singularidad de sus recursos y convertirse uno de los parques eco-arqueológicos más importantes del país, sobre todo si se adjuntan productos alternativos al turismo para aminorar la perturbación ecológica a la que han sido sometidos por varios decenios y que articulen a un sector más grande de la población local.

\section{Referencias}

Ávila Romero, A. (2015). Análisis del turismo alternativo en comunidades indígenas de Chiapas, México. Études caribéennes, 31-32. Recuperado de http://journals. openedition.org/etudescaribeennes/7601

Ayuntamiento de Palenque. (2007). Programa de Desarrollo Urbano de Palenque, Chiapas. 2007-2030, Síntesis ejecutiva. México: Secretaría de Obras Públicas, y Gobierno de Chiapas. Recuperado de http://www.ceieg.chiapas.gob.mx/ productos/files/OTSEINFRA/PROG_DES_URBANO_PALENQUE.pdf 
Beth, K. (2010). Tabasco y Chiapas. En Noble, J., Armstrong, K. y Benchwick, G. (Eds.) Lonely Planet, Mexico, 12th edition (pp. 709-780) Singapur: Lonely Planet Publications Pty Ltd.

Buch-Hanson, M. y Nelson, B. (1985). Marxist Geography and the concept of Territorial Structure. Antipode, 17(2-3), 50-59.

Coll-Hurtado, A. (2016). Espacio y ocio: el turismo en México (Colección: Temas Selectos de Geografía de México). México: Instituto de Geografía, UNAM.

Comisión Nacional del Agua (Conagua). (2016). Estadísticas del Agua en México. México: Conagua y Semarnat.

Comisión Nacional para el Conocimiento y Uso de la Biodiversidad (Conabio). (2013). Estrategia para la conservación y uso sustentable de la diversidad biológica del estado de Chiapas. México. Recuperado de https://bit.ly/2V8AYCu

Consejo Nacional de Evaluación de la Política de Desarrollo Social (Coneval). (2016). Informe de pobreza y evaluación en el estado de Chiapas. México: Coneval. Recuperado de https://www.coneval.org.mx/coordinacion/entidades/ Chiapas/Paginas/principal.aspx

Coronado, G. (2008). Insurgencia y turismo: reflexiones sobre el impacto del turista politizado en Chiapas. PASOS. Revista de Turismo y Patrimonio Cultural, 6(1), 53-68. doi: https://doi.org/10.25145/j.pasos.2008.06.005

Díaz, M. (2009). Tras las huellas de Palenque: las primeras exploraciones. LiminaR. Estudios sociales y humanísticos, 7(1), 104-134.

Escobar, P. (2010). Condiciones sociales, culturales y económicas de los municipios de Chiapas. México: Universidad Intercultural de Chiapas (UNICH).

Fondo Nacional de Fomento al Turismo (Fonatur). (2006). Planeación de Centros Turísticos: La experiencia y práctica de Fonatur. México: Fonatur. Recuperado de https://es.scribd.com/doc/50914092/Plan-de-centros-turisticos-la-exp-fonatur

Fondo Nacional de Fomento al Turismo (Fonatur). (2012). Planeación y diseño de nuevos proyectos, programa de asistencia técnica a estados y municipios. México: Fonatur. Recuperado de https://cedocvirtual.sectur.gob.mx/janium/ Documentos/11255.pdf

Gallegos, O. y López, A. (2004). Turismo y estructura territorial en Ciudad Juárez, México. Investigaciones Geográficas, 53, 141-162. doi: http://dx.doi. org/10.14350/rig.30219

García, E. (2004). Modificaciones al sistema de clasificación climática de Köppen. México: Serie Libros Núm. 6, Instituto de Geografía, UNAM. 
Garza, J. y Sánchez, Á. (2015). Estructura territorial del turismo en San Cristóbal de Las Casas, Chiapas, México. Cuadernos de Turismo, 35, 185-209. doi: http://dx.doi.org/10.6018/turismo.35.221571

Gobierno del Estado de Chiapas (2013). Programa Regional de Desarrollo, 2013-2018, Región XIII Maya. México: Comité de Planeación para el Desarrollo Regional (Coplader). Recuperado de http://www.ped.chiapas.gob.mx/ped/wpcontent/uploads/ProgReg/20132018/2013_PRD_13_Maya.pdf

Gómez, H., Pérez, M., Espinoza, J. y Márquez, M. (2015). Listado florístico del Parque Nacional Palenque. Chiapas, México. Botanical Sciences, 93(3), 559-578. doi: http://dx.doi.org/10.17129/botsci. 151

Hardy, A. (2004). Palenque, pasado y presente: monografía. México: EdySis

Instituto Nacional de Antropología e Historia (INAH). (2018). Museos y zonas arqueológicas con mayor afluencia al cierre 2017. México: INAH. Recuperado de http://www.datatur.sectur.gob.mx/SitePages/ActividadesCulturales.aspx

Instituto Nacional de Estadística y Geografía (INEGI). (2015). Encuesta Intercensal 2015. Aguascalientes: INEGI.

Instituto Nacional de Estadística y Geografía (INEGI). (2017). Anuario Estadístico y Geográfico de Chiapas 2017. Aguascalientes: INEGI. Recuperado de https:// www.datatur.sectur.gob.mx/ITxEF_Docs/CHIS_ANUARIO_PDF.pdf

Kostrowicki, J. (1986). Un concepto clave: organización espacial. México: Instituto de Geografía, UNAM.

Lastra, J. (1 de agosto de 2007). Desmantelan el tren Chiapas-Mayab, denuncian rieleros. La Jornada. Política. México.

Libert, A. (2019). Belleza escénica y conflicto territorial: la manufactura de la naturaleza en las Cascadas de Agua Azul, Chiapas, 6, 9-42.

Mariscal, A. (26 de diciembre de 2019). Iniciativa privada construirá carretera estratégica para proyectos extractivos en Chiapas. Aristegui Noticias. Recuperado de https://aristeguinoticias.com/2612/mexico

Mollinedo, G. (2014). Organización territorial de la economía turística en Guatemala (tesis de maestría). Facultad de Filosofía y Letras, UNAM, México.

Morales, H., Priego, A. y Bollo, M. (2017). Los paisajes físico-geográficos del estado de Chiapas, México a escala 1:250 000. Terra Digitalis, 1(1), 1-7. Recuperado de http://terradigitalis.igg.unam.mx/html/ojs3/index.php/terra_digitalis/article/view/8/0

Niño, N., Gallegos, C. y Castillo, N. (2008). Zonificación ecogeográfica para el ordenamiento territorial de Cascadas de Agua Azul, Chiapas, México. En M. E. Salinas (Coord.), El Ordenamiento territorial, experiencias internacionales (pp. 459-496). México: SEMARNAT, INE y Universidad de Guadalajara. 
Privalovskaya, G. (1983). Organización territorial de la industria. Cuba: Academia de Ciencias de Cuba.

Propín, E. y Sánchez, Á. (2001). Características básicas de la estructura territorial de la economía mexicana. Investigaciones Geográficas, 46, 148-163.

Secretaría de Agricultura y Desarrollo Rural (Sagarpa). (2016). Chiapas, agricultura, superficie cosechada por tipo de cultivo. México: SIAP. Recuperado de http:// www.ceieg.chiapas.gob.mx/perfiles/Inicio

Sánchez, Á., Mollinedo, G. y Propín, E. (2012). Estructura territorial del turismo en Guatemala. Investigaciones Geográficas, 78, 104-121. doi: http://dx.doi. org/10.14350/rig.32473

Sánchez Á. y Propín, E. (2010). Tipología de los núcleos turísticos primarios de América Central. Cuadernos de turismo, 25, 165-184.

Secretaría de Comunicaciones y Transportes (SCT). (2014). Programa Nacional de Infraestructura 2014-2018. Recuperado de http://www.ferroistmo.com.mx/ Programa-Nacional-de-Infraestructura-2014-2018.pdf

Secretaría de Medio Ambiente y Recursos Naturales (Semarnat) y Comisión Nacional de Áreas Naturales Protegidas (Conanp). (2017). Programa de Manejo Área de Protección de Flora y Fauna Cascadas de Agua Azul. México. Recuperado de http://www.conanp.gob.mx/acciones/pdf/PMCascadadeAguaAzul.pdf

Secretaría de Turismo (Sectur). (2018). Ocupación en hoteles y moteles por centro turístico, corte mensual. México: Datatur. Recuperado de http://www.datatur. sectur.gob.mx:81/Reportes/Reportes.aspx

Velázquez, G. y Cardona, G. (2017). El crecimiento económico en México y su relación con el turismo y medio ambiente (2003-2015), Mundo FESC, 7(13), 56-72. Recuperado de https://www.fesc.edu.co/Revistas/OJS/index.php/mundofesc/article/view/104

Villafuerte, D. (2004). La frontera sur de México. Del TLC México-Centroamérica al Plan Puebla Panamá. México: Plaza y Valdés, S.A.

Yurkievich, G. y Sánchez, Á. (2016). Estructura territorial de la actividad pesquera en Guaymas, Sonora. Investigaciones Geográficas, 91, 152-167. 